\title{
Machine learning-based advances in coronary computed tomography angiography
}

\author{
Mina M. Benjamin, Mark G. Rabbat \\ Department of Cardiology, Loyola University Medical Center, Maywood, Illinois, USA \\ Correspondence to: Mark G. Rabbat, MD, FACC, FAHA, FSCCT. Associate Professor of Medicine and Radiology, Division of Cardiology, Loyola \\ University Medical Center, Maywood, Illinois, USA. Email: mrabbat@lumc.edu.
}

Submitted Jan 26, 2021. Accepted for publication Feb 04, 2021.

doi: 10.21037/qims-21-99

View this article at: http://dx.doi.org/10.21037/qims-21-99

Coronary computed tomography angiography (CCTA) is an effective imaging modality increasingly accepted as a firstline test to diagnose coronary artery disease (CAD). CCTA stands out among other diagnostic modalities with an ability to image various stages of atherosclerosis, including plaque progression and rupture. Plaque burden and characteristics by CCTA have been shown to have prognostic implications for patient management (1). Also, detecting early subclinical $\mathrm{CAD}$ may allow for interventions aimed at preventing the progression of coronary plaque and reducing coronary events (2). The aim of this article is to discuss the innovative tools derived from CCTA using artificial intelligence (AI) which would aid in risk stratification and medical decision making for patients with CAD. For many observers, machine learning is treated as a "black box" in which data are analyzed and results produced, without attempting to understand how or why. This has the potential to cause significant issues if systematic biases are introduced and not recognized.

\section{Automated plaque characterization software and detecting culprit lesions}

AI has been used to develop deep convolutional neural networks (CNN) to classify CCTA in the correct Coronary Artery Disease Reporting and Data System (CAD-RADS) category and this was shown to be accurate and less timeconsuming (3). Some of the emerging technologies which use histologically validated, application-based tissue quantification to characterize atherosclerosis include the commercial software applications vascuCAP (Elucid Bioimaging, Boston, Massachusetts, USA) and
Sureplaque $^{\text {TM }}$ (V7.5; Vital Images, MN, USA).

Sureplaque ${ }^{\mathrm{TM}}$ software: SUREPlaque software (V7.5; Vital Images, MN, USA) uses color defined Hounsfield unit (HU) ranges to define plaque characteristics (Figure 1). The software is based on curved multiplanar reconstructions. It has shown good correlation to the morphometric parameters of atheroma, but fair correlation with regard to the relative plaque composition (4-6).

vascuCAP ${ }^{\mathrm{TM}}$ software: model-based quantification algorithms, as used by vascuCAP, aim to reduce interscan and interobserver variability and allow for detailed characterization of morphological features including positive remodeling, lipid-rich necrotic core, and coronary artery plaque burden $(7,8)$. van Assen et al. retrospectively studied 45 patients with suspected CAD of which 16 (36\%) experienced major adverse cardiac events within 12 months. The software was used to evaluate lumen area, wall area, stenosis percentage, wall thickness, plaque burden, remodeling ratio, calcified area, lipid rich necrotic core area and matrix area. Regression analysis using clinical risk factors resulted in a prognostic accuracy of $63 \%$ with a corresponding area under the curve (AUC) of 0.587 . The use of morphologic features alone resulted in an increased accuracy of $77 \%$ with an AUC of 0.94 . Combining both clinical risk factors and morphological features in a multivariate logistic regression analysis increased the accuracy to $87 \%$ with a similar AUC of 0.924 .

QAngio $^{\mathrm{TM}}$ software: a semiautomated plaque analysis software (QAngio CT Research Edition v2.02, Medis Medical Imaging Systems, Leiden, the Netherlands), which has been validated for accuracy (9). This software was used in the study by Park et al. to evaluate the 


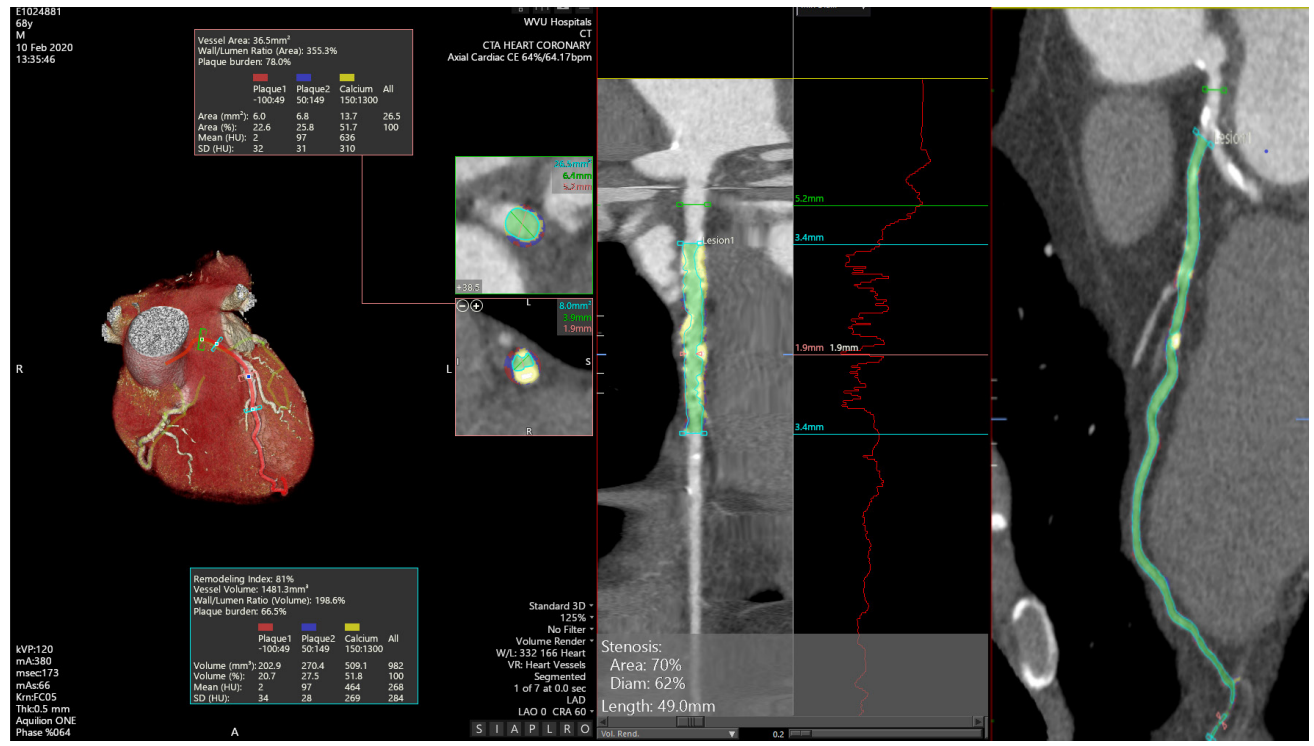

Figure 1 Examples of sureplaque ${ }^{\mathrm{TM}}$ software analysis of plaque composition and vessel volume.

association between atherosclerotic plaque characteristics by computed tomography angiography (CTA), and lesion ischemia by fractional flow reserve (FFR). High-risk plaque characteristics by coronary CTA were defined as: (I) positive remodeling, lesion diameter/reference diameter $>1.10$; (II) low attenuation plaque, any voxel $<30 \mathrm{HU}$; and (III) spotty calcifications, nodular calcified plaque $<3 \mathrm{~mm}$. In multivariable analyses, a stepwise increased risk of ischemia was observed for 1 [odds ratio $(\mathrm{OR})$ : $4.0, \mathrm{P}<0.001$ ] and $\geq 2$ (OR: 12.1, $\mathrm{P}<0.001$ ) high-risk features. These findings were risk feature dependent, with positive remodeling (OR: 5.3, $\mathrm{P}<0.001)$ and low attenuation plaque (OR: 2.1, $\mathrm{P}=0.038)$ associated with ischemia, but not spotty calcification (10).

CardIQ Xpress Pro: de Graaf et al. studied the feasibility of this fully automatic software (CardIQ Xpress Pro, GE) in 57 patients who underwent CCTA prior to intravascular ultrasound virtual histology. CCTA plaque volume was characterized in four different plaque types; necrotic core, dense calcium, fibrotic and fibro-fatty tissue. Assessment of plaque volume using the software in 108 lesions showed excellent correlation with intravascular ultrasound virtual histology $(\mathrm{r}=0.928, \mathrm{P}<0.001)(11)$.

Al'Aref et al. pioneered the task of putting the large volume of data obtained by plaque analysis software into a practical algorithm using machine learning. The investigators combined the data from quantitative and visual coronary CCTA analysis in order to identify culprit lesions in patients with subsequent acute coronary syndrome (12).
This research was a secondary analysis of the ICONIC (Incident COroNary Syndromes Identified by Computed Tomography) study, a nested case-control study from the CONFIRM (Coronary CT Angiography Evaluation for Clinical Outcomes: An International Multicenter) registry (13). In the ICONIC study, 234 patients who had undergone CCTA and subsequently developed an acute coronary syndrome were matched with 234 control subjects without acute coronary syndrome, and quantitative CCTA plaque analysis was performed. Al'Aref et al. trained and tested a machine learning model using data on 46 plaque variables from 124 patients with invasive coronary angiography-confirmed culprit lesions. The resulting model had an AUC for detecting culprit lesions of 0.774 (95\% confidence interval: 0.758 to 0.790 ). The model had a specificity of $89 \%$ for predicting non-culprit lesions in the 234 patients without acute coronary syndrome. The most important parameter was the distance between the start of the lesion and the minimal lumen diameter, followed by plaque volume and luminal area stenosis. Among the top 20 features used by the model, there were several quantitative CCTA measures, including the volume of dense calcium, fibrous plaque, and fibrous-fatty plaque. However, low-attenuation plaque and visually assessed highrisk plaque features were not among the top 20 features. This machine learning model has not undergone external validation yet.

Some issues must be resolved before these automated 


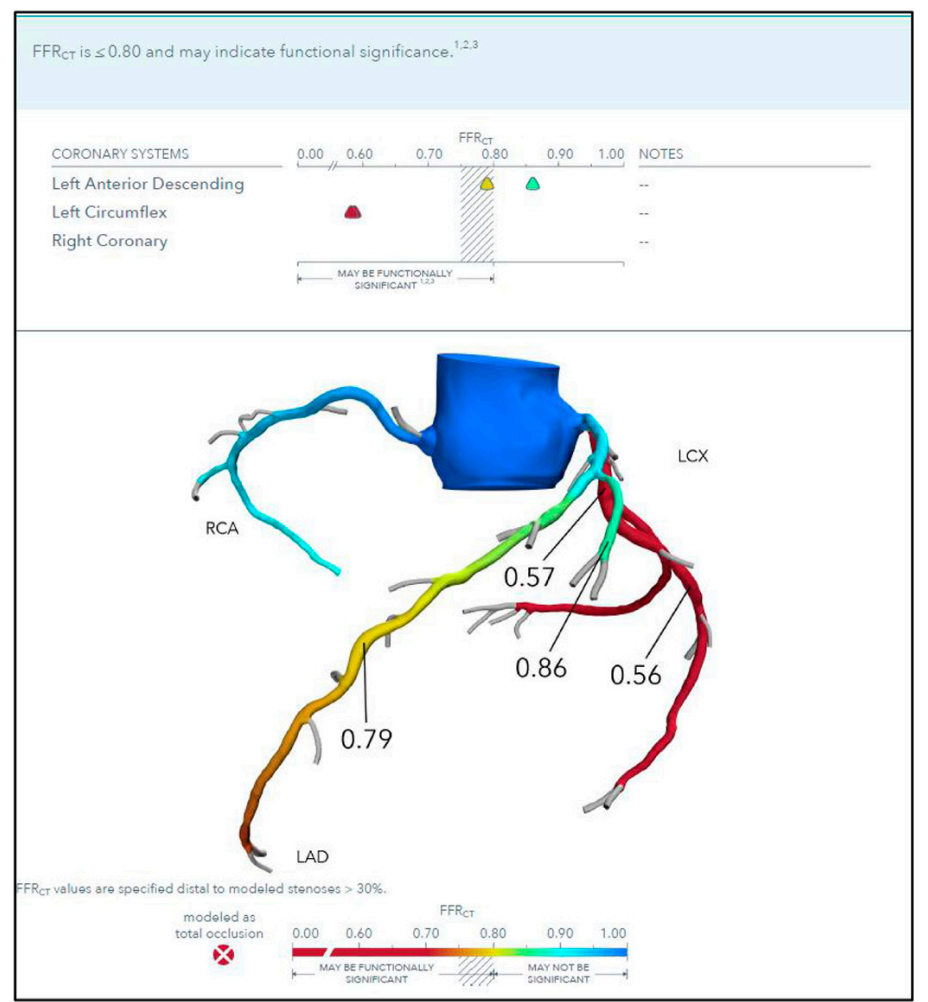

Figure 2 Example of $\mathrm{FFR}_{\mathrm{CT}}$ report for a patient with $\mathrm{CAD}$. $\mathrm{FFR}_{\mathrm{CT}}$, coronary computed tomography angiography-derived fractional flow reserve; CAD, coronary artery disease; LCX, left circumflex artery; RCA, right coronary artery.

software products can be adopted into every-day clinical practice. The most pressing is high reproducibility which needs to be firmly established. Second, many of these applications are limited by pre-specified thresholds that do not consider various technical limitations, including different scanners and scan protocols. Third, the accuracy of the software has to be defined for different components of plaque. While CCTA automated software was shown to reliably differentiate noncalcified, mixed, and calcified plaques (14), further subclassification of noncalcified plaque into fibrous or fatty components using CT attenuation values is less reliable (15). CCTA has a relatively low soft tissue contrast resolution, so attenuation differences between varying plaque components can be challenging.

\section{CCTA-derived FFR (FFR $\left.\mathbf{F}_{\mathrm{CT}}\right)$}

The Achilles heel of CCTA alone is not being able to define the hemodynamic significance of coronary lesions. Only 35 $40 \%$ of patients undergoing invasive coronary angiography are found to have anatomically obstructive CAD (16). Thus, identifying patients with both anatomically and functionally significant CAD before catheterization using noninvasive testing could dramatically reduce the need for unnecessary invasive and downstream testing. Machine-learning CCTA applications have allowed for noninvasive assessment of the functional significance of atherosclerotic lesions from

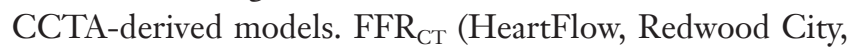
California, USA) is a technology whereby patient-specific models of blood flow are constructed from CCTA images and used to noninvasively derive FFR (Figure 2) and has been validated in multiple prospective multicenter clinical trials $(17,18)$. The technology uses deep learning algorithms to extract lumen boundaries from CCTA using an approach validated against optical coherence tomography (OCT), and it creates a patient-specific physiologic model based on form-function principles and computational fluid dynamic analysis to compute the blood flow solution $(19,20)$.

Several recent reports have examined the relationship between various CCTA-derived plaque characteristics and the ability to predict ischemia, as measured by various techniques including myocardial perfusion and FFR. In the CORE320 (Combined Noninvasive Coronary Angiography and Myocardial Perfusion Imaging Using 320 Detector 
Computed Tomography) study, CCTA-derived features including percent stenosis, percent atheroma volume, and the impression of "vulnerable plaque" independently predicted myocardial ischemia by single-photon emission computed tomography (SPECT) (21). Gaur et al. (22) investigated 254 patients and reported that noncalcified plaque volume predicted an FFR cutoff value of 0.80 , independent of stenosis severity. These results were confirmed by a recent post hoc analysis from the singlecenter PACIFIC (Prospective Comparison of Cardiac PET/ CT, SPECT/CT Perfusion Imaging and CCTA With Invasive Coronary Angiography) trial showing that positive remodeling and noncalcified atherosclerotic plaque volume were associated with decreased absolute myocardial blood flow by $\left[{ }^{15} \mathrm{O}\right] \mathrm{H}_{2} \mathrm{O}$ PET and invasive FFR (23). The NXT (Analysis of Coronary Blood Flow Using CT Angiography: Next Steps) trial demonstrated that the diagnostic accuracy of $\mathrm{FFR}_{\mathrm{CT}}$ (AUC: $0.90 ; 95 \%$ confidence interval: 0.87 to 0.94) was significantly greater than that of CCTA alone (0.81; $95 \%$ confidence interval: 0.76 to 0.87$)$ (24). The PACIFIC study also compared the diagnostic accuracy of various modalities using invasive 3 -vessel FFR as the gold standard and found that the AUC on a per-vessel basis was significantly greater for $\mathrm{FFR}_{\mathrm{CT}}$ (0.94) compared to CCTA (0.83), SPECT (0.70), and PET (0.87) $(\mathrm{P}<0.001$ for all $)(25)$.

$\mathrm{FFR}_{\mathrm{CT}}$ is being investigated as a tool in clinical decisionmaking. Rabbat et al. reported the safe deferral of invasive coronary angiography in patients with stable CAD using a diagnostic strategy of $\mathrm{FFR}_{\mathrm{CT}}$ (26). Of the 387 patients studied, 121 patients $(32 \%)$ had at least one vessel with $\geq 50 \%$ diameter stenosis; $67 / 121$ (55\%) patients had at least one vessel with $\mathrm{FFR}_{\mathrm{CT}} \leq 0.80 ; 55 / 121(45 \%)$ underwent invasive coronary angiography; and 34 were revascularized. Compared to CCTA alone, CCTA with selective FFR $_{\mathrm{CT}}$ reduced the rates of invasive coronary angiography ( $45 \%$ vs. $80 \%$ ) for those with obstructive CAD. Using coronary CTA with selective $\mathrm{FFR}_{\mathrm{CT}}$, no major adverse cardiac events occurred over a mean follow-up of 440 days. Ongoing prospective, pragmatic, randomized clinic trials such as PRECISE (Prospective Randomized Trial of the Optimal Evaluation of Cardiac Symptoms and Revascularization) will shed light on the role of using $\mathrm{FFR}_{\mathrm{CT}}$ as a diagnostic strategy for patients with suspected CAD. In September 2019, the Food and Drug Administration approved HeartFlow Planner, a real-time virtual modeling tool for CAD intervention. HeartFlow Planner provides luminal remodeling using computer software enabling recalculation of the FFR after virtual removal of coronary artery stenoses and prediction of post-percutaneous coronary intervention (PCI) FFR $_{\mathrm{CT}}(27,28)$

\section{Clinical perspective}

The application of machine learning into day-to-day CCTA reading is not ready for prime time yet. Each AI-enabled software requires rigorous validation prior to clinical implementation. There are concerns about unforeseen biases associated with socioeconomic and racial backgrounds of populations (29). Also, at present, some quantitative plaque analysis tools are still time-consuming, and this limits their application in clinical practice. Fully automated CCTA assessment are being developed and need to be validated before being incorporated in clinical practice. Randomized controlled trials that assess whether tailoring therapies based on quantitative CCTA plaque assessments leads to more favorable plaque characteristics and improved clinical outcomes, are needed. Future generation CCTAprocessing software will incorporate additional information from quantitative plaque characteristics and machine learning to facilitate individualized patient management in order to improve clinical outcomes.

\section{Acknowledgments}

Funding: None.

\section{Footnote}

Provenance and Peer Review: This article was commissioned by the editorial office, Quantitative Imaging in Medicine and Surgery. The article did not undergo external peer review.

Conflicts of Interest: Both authors have completed the ICMJE uniform disclosure form (available at http:// dx.doi.org/10.21037/qims-21-99). Dr. MGR: Consultant: HeartFlow. Dr. MMB has no conflicts of interest to declare.

Open Access Statement: This is an Open Access article distributed in accordance with the Creative Commons Attribution-NonCommercial-NoDerivs 4.0 International License (CC BY-NC-ND 4.0), which permits the noncommercial replication and distribution of the article with the strict proviso that no changes or edits are made and the original work is properly cited (including links to both the formal publication through the relevant DOI and the license). See: https://creativecommons.org/licenses/by-nc-nd/4.0/. 


\section{References}

1. Muscogiuri G, Van Assen M, Tesche C, De Cecco CN, Chiesa M, Scafuri S, Guglielmo M, Baggiano A, Fusini L, Guaricci AI, Rabbat MG, Pontone G. Artificial Intelligence in Coronary Computed Tomography Angiography: From Anatomy to Prognosis. Biomed Res Int 2020;2020:6649410.

2. Ahmadi A, Argulian E, Leipsic J, Newby DE, Narula J. From Subclinical Atherosclerosis to Plaque Progression and Acute Coronary Events: JACC State-of-the-Art Review. J Am Coll Cardiol 2019;74:1608-17.

3. Muscogiuri G, Chiesa M, Trotta M, Gatti M, Palmisano V, Dell'Aversana S, Baessato F, Cavaliere A, Cicala G, Loffreno A, Rizzon G, Guglielmo M, Baggiano A, Fusini L, Saba L, Andreini D, Pepi M, Rabbat MG, Guaricci AI, De Cecco CN, Colombo G, Pontone G. Performance of a deep learning algorithm for the evaluation of CAD-RADS classification with CCTA. Atherosclerosis 2020;294:25-32.

4. Akutagawa O, Kijima Y, Kume K, Sakai T, Okura A, Ide K, Iwasaki S, Hata T. Feasibility and limitation of coronary plaque volumetry by contrast-enhanced 64row multi-detector computed tomography. Int J Cardiol 2011;150:118-20.

5. Brodoefel H, Burgstahler C, Heuschmid M, Reimann A, Khosa F, Kopp A, Schroeder S, Claussen CD, Clouse ME. Accuracy of dual-source CT in the characterisation of noncalcified plaque: use of a colour-coded analysis compared with virtual histology intravascular ultrasound. Br J Radiol 2009;82:805-12.

6. Benjamin M, Banga S, Kim C, Hamirani Y, Zeb I, Kadiyala $M$. Concordance of CT-FFR with invasive angiography is affected by image quality and coronary vessel volume/mass ratio. J Cardiovasc Comput Tomogr 2020;14:S49-50.

7. Sheahan M, Ma X, Paik D, Obuchowski NA, St Pierre S, Newman WP 3rd, Rae G, Perlman ES, Rosol M, Keith JC Jr, Buckler AJ. Atherosclerotic Plaque Tissue: Noninvasive Quantitative Assessment of Characteristics with Softwareaided Measurements from Conventional CT Angiography. Radiology 2018;286:622-31.

8. van Assen M, Varga-Szemes A, Schoepf UJ, Duguay TM, Hudson HT, Egorova S, Johnson K, St Pierre S, Zaki B, Oudkerk M, Vliegenthart R, Buckler AJ. Automated plaque analysis for the prognostication of major adverse cardiac events. Eur J Radiol 2019;116:76-83.

9. Park HB, Lee BK, Shin S, Heo R, Arsanjani R, Kitslaar PH, Broersen A, Dijkstra J, Ahn SG, Min JK, Chang HJ, Hong MK, Jang Y, Chung N. Clinical Feasibility of 3D Automated Coronary Atherosclerotic Plaque Quantification Algorithm on Coronary Computed Tomography Angiography: Comparison with Intravascular Ultrasound. Eur Radiol 2015;25:3073-83.

10. Park HB, Heo R, Ó Hartaigh B, Cho I, Gransar H, Nakazato R, Leipsic J, Mancini GBJ, Koo BK, Otake H, Budoff MJ, Berman DS, Erglis A, Chang HJ, Min JK. Atherosclerotic plaque characteristics by CT angiography identify coronary lesions that cause ischemia: a direct comparison to fractional flow reserve. JACC Cardiovasc Imaging 2015 ;8:1-10.

11. de Graaf MA, Broersen A, Kitslaar PH, Roos CJ, Dijkstra J, Lelieveldt BP, Jukema JW, Schalij MJ, Delgado V, Bax JJ, Reiber JH, Scholte AJ. Automatic quantification and characterization of coronary atherosclerosis with computed tomography coronary angiography: cross-correlation with intravascular ultrasound virtual histology. Int J Cardiovasc Imaging 2013;29:1177-90.

12. Al'Aref SJ, Singh G, Choi JW, Xu Z, Maliakal G, van Rosendael AR, Lee BC, Fatima Z, Andreini D, Bax JJ, Cademartiri F, Chinnaiyan K, Chow BJW, Conte E, Cury RC, Feuchtner G, Hadamitzky M, Kim YJ, Lee SE, Leipsic JA, Maffei E, Marques H, Plank F, Pontone G, Raff GL, Villines TC, Weirich HG, Cho I, Danad I, Han D, Heo R, Lee JH, Rizvi A, Stuijfzand WJ, Gransar H, Lu Y, Sung JM, Park HB, Berman DS, Budoff MJ, Samady H, Stone PH, Virmani R, Narula J, Chang HJ, Lin FY, Baskaran L, Shaw LJ, Min JK. A Boosted Ensemble Algorithm for Determination of Plaque Stability in HighRisk Patients on Coronary CTA. JACC Cardiovasc Imaging 2020;13:2162-73.

13. Chang HJ, Lin FY, Lee SE, Andreini D, Bax J, Cademartiri F, Chinnaiyan K, Chow BJW, Conte E, Cury RC, Feuchtner G, Hadamitzky M, Kim YJ, Leipsic J, Maffei E, Marques H, Plank F, Pontone G, Raff GL, van Rosendael AR, Villines TC, Weirich HG, Al'Aref SJ, Baskaran L, Cho I, Danad I, Han D, Heo R, Lee JH, Rivzi A, Stuijfzand WJ, Gransar H, Lu Y, Sung JM, Park HB, Berman DS, Budoff MJ, Samady H, Shaw LJ, Stone PH, Virmani R, Narula J, Min JK. Coronary Atherosclerotic Precursors of Acute Coronary Syndromes. J Am Coll Cardiol 2018;71:2511-22.

14. Leschka S, Seitun S, Dettmer M, Baumuller S, Stolzmann P, Goetti R, Scheffel H, Feuchtner G, Wunnicke K, Wildermuth S, Oehlschlegel C, Marincek B, Jochum W, Alkadhi H. Ex vivo evaluation of coronary atherosclerotic plaques: characterization with dual-source CT in comparison with histopathology. J Cardiovasc Comput Tomogr 2010;4:301-8. 
15. Hur J, Kim YJ, Lee HJ, Nam JE, Choe KO, Seo JS, Choi DH, Kim JS, Choi BW. Quantification and characterization of obstructive coronary plaques using 64-slice computed tomography: a comparison with intravascular ultrasound. J Comput Assist Tomogr 2009;33:186-92.

16. Patel MR, Peterson ED, Dai D, Brennan JM, Redberg RF, Anderson HV, Brindis RG, Douglas PS. Low diagnostic yield of elective coronary angiography. $\mathrm{N}$ Engl J Med 2010;362:886-95.

17. Meijboom WB, Van Mieghem CA, van Pelt N, Weustink A, Pugliese F, Mollet NR, Boersma E, Regar E, van Geuns RJ, de Jaegere PJ, Serruys PW, Krestin GP, de Feyter PJ. Comprehensive assessment of coronary artery stenoses: computed tomography coronary angiography versus conventional coronary angiography and correlation with fractional flow reserve in patients with stable angina. J Am Coll Cardiol 2008;52:636-43.

18. Rabbat MG, Berman DS, Kern M, Raff G, Chinnaiyan K, Koweek L, Shaw LJ, Blanke P, Scherer M, Jensen JM, Lesser J, Norgaard BL, Pontone G, De Bruyne B, Bax JJ, Leipsic J. Interpreting results of coronary computed tomography angiography-derived fractional flow reserve in clinical practice. J Cardiovasc Comput Tomogr 2017;11:383-8.

19. Taylor CA, Fonte TA, Min JK. Computational fluid dynamics applied to cardiac computed tomography for noninvasive quantification of fractional flow reserve: scientific basis. J Am Coll Cardiol 2013;61:2233-41.

20. Uzu K, Otake H, Choi G, Toba T, Kim HJ, Roy A, Schaap M, Grady L, Kawata M, Shinke T, Taylor CA, Hirata KI. Lumen boundaries extracted from coronary computed tomography angiography on computed fractional flow reserve (FFRCT): validation with optical coherence tomography. EuroIntervention 2019;14:e1609-18.

21. Bakhshi H, Meyghani Z, Kishi S, Magalhaes TA, Vavere A, Kitslaar PH, George RT, Niinuma H, Reiber JHC, Betoko A, Matheson M, Rochitte CE, Di Carli MF, Cox C, Lima JAC, Arbab-Zadeh A. Comparative Effectiveness of CT-Derived Atherosclerotic Plaque Metrics for Predicting Myocardial Ischemia. JACC Cardiovasc Imaging 2019;12:1367-76.

22. Gaur S, Ovrehus KA, Dey D, Leipsic J, Botker HE, Jensen JM, Narula J, Ahmadi A, Achenbach S, Ko BS, Christiansen EH, Kaltoft AK, Berman DS, Bezerra H, Lassen JF, Norgaard BL. Coronary plaque quantification and fractional flow reserve by coronary computed tomography angiography identify ischaemia-causing lesions. Eur Heart J 2016;37:1220-7.

23. Driessen RS, Stuijfzand WJ, Raijmakers PG, Danad I, Min JK, Leipsic JA, Ahmadi A, Narula J, van de Ven PM, Huisman MC, Lammertsma AA, van Rossum AC, van Royen N, Knaapen P. Effect of Plaque Burden and Morphology on Myocardial Blood Flow and Fractional Flow Reserve. J Am Coll Cardiol 2018;71:499-509.

24. Nørgaard BL, Leipsic J, Gaur S, Seneviratne S, Ko BS, Ito H, Jensen JM, Mauri L, De Bruyne B, Bezerra H, Osawa K, Marwan M, Naber C, Erglis A, Park SJ, Christiansen EH, Kaltoft A, Lassen JF, Bøtker HE, Achenbach S; NXT Trial Study Group. Diagnostic performance of noninvasive fractional flow reserve derived from coronary computed tomography angiography in suspected coronary artery disease: the NXT trial (Analysis of Coronary Blood Flow Using CT Angiography: Next Steps). J Am Coll Cardiol 2014;63:1145-55.

25. Driessen RS, Danad I, Stuijfzand WJ, Raijmakers PG, Schumacher SP, van Diemen PA, Leipsic JA, Knuuti J, Underwood SR, van de Ven PM, van Rossum AC, Taylor CA, Knaapen P. Comparison of Coronary Computed Tomography Angiography, Fractional Flow Reserve, and Perfusion Imaging for Ischemia Diagnosis. J Am Coll Cardiol 2019;73:161-73.

26. Rabbat M, Leipsic J, Bax J, Kauh B, Verma R, Doukas D, Allen S, Pontone G, Wilber D, Mathew V, Rogers C, Lopez J. Fractional Flow Reserve Derived from Coronary Computed Tomography Angiography Safely Defers Invasive Coronary Angiography in Patients with Stable Coronary Artery Disease. J Clin Med 2020;9:604.

27. Modi BN, Sankaran S, Kim HJ, Ellis H, Rogers C, Taylor CA, Rajani R, Perera D. Predicting the Physiological Effect of Revascularization in Serially Diseased Coronary Arteries. Circ Cardiovasc Interv 2019;12:e007577.

28. Conte E, Sonck J, Mushtaq S, Collet C, Mizukami T, Barbato E, Tanzilli A, Nicoli F, De Bruyne B, Andreini D. FFRCT and CT perfusion: A review on the evaluation of functional impact of coronary artery stenosis by cardiac CT. Int J Cardiol 2020;300:289-96.

29. Tat E, Bhatt DL, Rabbat MG. Addressing bias: artificial intelligence in cardiovascular medicine. Lancet Digit Health 2020;2:e635-6.

Cite this article as: Benjamin MM, Rabbat MG. Machine learning-based advances in coronary computed tomography angiography. Quant Imaging Med Surg 2021;11(6):2208-2213. doi: 10.21037/qims-21-99 